\title{
Monod kinetics rather than a first-order degradation model explains atrazine fate in soil mini-columns: Implications for pesticide fate modelling
}

\author{
K. Cheyns*, J. Mertens, J. Diels, E. Smolders, D. Springael* \\ Division soil and water management, Katholieke Universiteit Leuven, Kasteelpark Arenberg 20, B-3001 Heverlee, Belgium \\ Population dynamics of pesticide degrading population should be taken into account when predictions of pesticide fate are made to avoid \\ underestimation of pesticide break-through towards groundwater.
}

\section{A R T I C L E I N F O}

\section{Article history:}

Received 8 July 2009

Received in revised form

16 December 2009

Accepted 23 December 2009

\section{Keywords:}

Atrazine

Biodegradation

Inverse modelling

HYDRUS-1D

Monod kinetics

\begin{abstract}
A B S T R A C T
Pesticide transport models commonly assume first-order pesticide degradation kinetics for describing reactive transport in soil. This assumption was assessed in mini-column studies with associated batch degradation tests. Soil mini-columns were irrigated with atrazine in two intermittent steps of about 30 days separated by 161 days application of artificial rain water. Atrazine concentration in the effluent peaked to that of the influent concentration after initial break-through but sharply decreased while influx was sustained, suggesting a degradation lag phase. The same pattern was displayed in the second step but peak height and percentage of atrazine recovered in the effluent were lower. A Monod model with biomass decay was successfully calibrated to this data. The model was successfully evaluated against batch degradation data and mini-column experiments at lower flow rate. The study suggested that first-order degradation models may underestimate risk of pesticide leaching if the pesticide degradation potential needs amplification during degradation.
\end{abstract}

(ㄷ) 2010 Elsevier Ltd. All rights reserved.

\section{Introduction}

Biodegradation and sorption kinetics are crucial processes that control the transport of pesticides through the unsaturated zone of soils.

Sorption of most pesticides in soil is mainly related to soil organic matter (SOM) content (Spark and Swift, 2002; Coquet and Barriuso, 2002). The SOM decreases with depth in a soil profile (Jobbagy and Jackson, 2000). Therefore, in deeper soil layers, kinetics of pesticide degradation might be the most important factor which governs pesticide leaching towards groundwater.

Pesticide mineralization or degradation kinetics in soils at larger scale is commonly described in pesticide transport models with a first-order approach (e.g. HYDRUS model: Simunek et al., 2005; PESTRAS model: Tiktak et al., 1994; Dubus et al., 2004). A first-order approach is however in contrast with laboratory mineralization experiments where a lag period is often observed (Alexander, 1999; De Wilde et al., 2009; Sniegowski et al., 2009). One of the explanations for this lag period as proposed by Alexander (1999), is the proliferation of small microbial populations able to degrade the pesticide by using it as a carbon, energy and/or nutrient source.

\footnotetext{
* Corresponding authors. Tel.: +32 163217 61; fax: +32 16321997.

E-mail address: Karlien.Cheyns@ees.kuleuven.be (K. Cheyns).
}

Alexander (1999) describes different batch studies where the lag period of pesticide mineralization decreases after intermittent pesticide additions to the soils. The greater degradation rate after subsequent additions was supposed to result from increases in the degrading biomass following repeated treatment with the pesticide. The same accounts for a soil profile, where larger lag periods are observed in deeper soil layers, less exposed to pesticides (Vanderheyden et al., 1997; Bending and Rodriguez-Cruz, 2007). Therefore, as suggested by Fomsgaard (1997), models taking microbiological growth into account might be recommended to predict the fate of low pesticide concentrations in subsoils.

The relationship between microbial growth and substrate concentration has been successfully described using Monod kinetics (Monod, 1949) in aqueous (Simkins and Alexander, 1984; Jones and Alexander, 1986) and soil systems (Shelton and Doherty, 1997). Simkins and Alexander (1984) propose 6 different models, depending on the initial substrate concentration and initial cell density. One of the models, a logistic simplification, can be used when the substrate is initially present in much lower concentrations than the saturated pesticide concentration for the degrading population. Using this type of kinetics, Sniegowski et al. (2009) predicted the mineralization capacity of a biofilter for the herbicide linuron, during and after the addition of linuron to the biofilter.

The growth-linked biodegradation kinetics, well described for batch degradation studies, are not commonly used in pesticide 
transport models. Recently Monod-type growth-linked degradation kinetics was implemented in the HYDRUS-1D model (Simunek et al., 2005). This model has been validated to describe metalaxyl and linuron transport in column displacement experiments in artificial substrates (De Wilde et al., 2009). The validity of this model has not yet been tested for displacement experiments in soil profiles. In addition, it is not yet tested for such displacement experiments how intermittent periods of non-pesticide applications affect lag times of degradation. The latter is a scenario relevant at field scale, where the presence or absence of the pesticide can cause respectively growth or decay of the pesticide degrading biomass.

The objectives of this study were to verify degradation kinetics with dedicated batch and mini-column studies and to model them with a reaction transport model (described by De Wilde et al. (2009)). Therefore a mini-column experiment was setup and 2 step-additions of atrazine (AT) were applied with an interval of 161 days. In this way the growth and decay rate of the AT degrading population could be estimated in presence and absence of AT. To parameterise the model, an inverse modelling framework combining a sensitivity analysis (Morris Sensitivity Analysis) with an inverse modelling approach (Shuffled Complex Evolution Metropolis) (Vrugt et al., 2003) was adopted. To evaluate the model the kinetics of AT degradation in the subsoil was determined in soil suspension batch tests setup before and at the end of the minicolumn experiment and in a mini-column experiment operated at a lower flow rate. In all experiments subsoil samples are used to emphasize the importance of degradation kinetics during pesticide transport when sorption is low.

\section{Materials en methods}

\subsection{Soil mini-column setup}

The soil mini-column setup consisted of 4 mini-columns A, B, C and D (length $6.5 \mathrm{~cm}$, internal diameter $3 \mathrm{~cm}$ ), each containing $80 \mathrm{~g}$ soil, sieved at $2 \mathrm{~mm}$, with a bulk density of $1.5 \mathrm{~g} \mathrm{~cm}^{-3}$. The soil was a subsoil collected at $30-45 \mathrm{~cm}$ depth in an agricultural field (Beverst, Belgium) which had been annually treated by AT since 1973. The soil was sieved field moist and was stored at $4{ }^{\circ} \mathrm{C}$ pending the experiments. Characteristics of the soil were: $\mathrm{pH} 6.5,0.44 \%$ carbon and $0.05 \% \mathrm{~N}$. The texture of the soil consisted of $33.4 \%$ sand, $12.7 \%$ clay and $51.2 \%$ silt.

In the mini-columns, glass filter plates (ROBU P5, pore size $1.0-1.6 \mu \mathrm{m}$ ) were placed below the soil and a pressure head of $-100 \mathrm{~cm}$ was applied using a vacuum pump. Influent consisting of a salt solution with (AT solution) or without AT was added with a rate of $21.4 \mathrm{~mm}^{-1}{ }^{-1}$ for mini-columns $A$ and $B$ and of $8.3 \mathrm{~mm} \mathrm{day}^{-1}$ for mini-columns $C$ and D using a peristaltic pump (205 a, Watson-Marlow, UK). The salt solution was composed to simulate the soil solution and contained (per liter): $214.4 \mathrm{mg} \mathrm{NaHCO}, 83.0 \mathrm{mg} \mathrm{NaNO}, 31.2 \mathrm{mg} \mathrm{MgSO}_{4} .7 \mathrm{H}_{2} \mathrm{O}, 46.4 \mathrm{mg} \mathrm{MgCl}_{2} .6 \mathrm{H}_{2} \mathrm{O}$, $245.2 \mathrm{mg} \mathrm{CaCl} 2.2 \mathrm{H}_{2} \mathrm{O}$ and $6.1 \mathrm{mg} \mathrm{KCl}$. A stock solution of AT (Sigma-Aldrich, Belgium) was prepared in acetone $\left(10 \mathrm{~g} \mathrm{~L}^{-1}\right)$. The AT stock solution was evaporated to dissolve the herbicide in the salt solution to a final concentration of $12 \mathrm{mg} \mathrm{L}^{-1}$ (step 1) and $15 \mathrm{mg} \mathrm{L}^{-1}$ (step 2).

Before applying the AT solution the mini-columns were leached at $20^{\circ} \mathrm{C}$ with at least 7 pore volumes of salt solution without AT, until equilibrium was reached of the ionic concentration in the effluent. The AT solution was then added during 31 days (step 1). After this period the mini-columns were irrigated for 161 days with the salt solution without AT, to simulate a period without AT. The second step input of the AT solution was applied during 28 days. The leachates were collected in $250 \mathrm{~mL}$ glass bottles which were periodically analysed for AT concentration.

A bromide break-through curve (BTC) was obtained to estimate soil hydraulic parameters. The non-reactive tracer was added as a solution of $1 \mathrm{mM} \mathrm{KBr}$ in the salt solution before the AT application, during the leaching period. The $\mathrm{KBr}$ solution was added as a pulse during 0.3 days in mini-columns $A$ and $B$ operated at the high flow rate and during 0.69 days in mini-columns $\mathrm{C}$ and $\mathrm{D}$ operated at the low flow rate.

\subsection{Batch degradation experiments}

The kinetics of AT degradation in the soil in batch systems were determined before and after the mini-column experiment. Batch experiments were prepared in erlenmeyers contained $2 \mathrm{~g}$ of soil in $25 \mathrm{~mL}$ of the AT salt solution ( $13 \mathrm{mg} \mathrm{AT} \mathrm{L}^{-1}$ ) and were carried out in triplicate. The suspensions were placed on a horizontal shaker (125 rpm) and incubated at $20^{\circ} \mathrm{C}\left( \pm 1^{\circ} \mathrm{C}\right)$. The AT concentration was measured in the solution at different time intervals. The soil samples tested were $(i)$ soil from the field, as used in the mini-column experiment but stored at $4{ }^{\circ} \mathrm{C}$ for 200 days and (ii) soil from the mini-column experiments from the top $(1 \mathrm{~cm})$ and bottom $(1 \mathrm{~cm})$ of soil mini-columns A and B, immediately treated after ending the mini-column experiment at day 220. All soil samples from the mini-column experiment were mixed thoroughly before analysis.

\subsection{Analytical methods}

Concentrations of AT were measured by reverse-phase HPLC. The LaChrom HPLC-UV-VIS system (Merck, Hitachi) was equipped with a LiChroCART 4-4 Purospher STAR RP-18 endcapped guardcolumn and a LiChroCART 125-4 Purospher STAR RP-18 endcapped column (125 mm in length; $4 \mathrm{~mm}$ in diameter) packed with silica beads (particle size $5 \mu \mathrm{m}$ ) as stationary phase. The mobile phase was composed of acetonitrile and $\mathrm{mQ}$ water (70/30). The flow rate was $1 \mathrm{~mL} \mathrm{~min}^{-1}$ and the UV detector was set to $220 \mathrm{~nm}$. The chromatogram peaks of the analysed compounds were identified and quantified by comparison with external standards of AT. The limit of quantification was $1 \mathrm{mg} \mathrm{L}^{-1}$

Bromide concentrations were analysed in the effluent solutions using ion chromatography (DIONEX-ICS-2000, equipped with an AS15 $2 \mathrm{~mm}$ column, $\mathrm{KOH}$ was used as eluent). Bromide detection was performed by conductivity with a detection limit of $0.001 \mathrm{mM}$.

\subsection{Degradation and reactive transport model development}

Zero- and first-order pesticide degradation models, which do not describe lag periods, could not be used to describe pesticide degradation kinetics in the batch experiments and during transport through the mini-columns. Therefore, a logistic model based on the Monod kinetics was applied. Microbial growth and pesticide degradation can be described simultaneously by equations (1) and (2).

$\frac{d X}{d t}=\left(\mu_{m} * \frac{C_{l}}{K_{s}+C_{l}}\right) X-k_{\text {decay }} X$

$\frac{d C}{d t}=-\frac{1}{Y}\left(\mu_{m} * \frac{C_{l}}{K_{s}+C_{l}}\right) X$

in which $X$ is the total AT degrading biomass (ADB) concentration in soil, expressed in AT concentration units on a whole soil volume basis $\left[\mathrm{mg} \mathrm{L}^{-1}\right.$ tot $], C_{l}$ is the AT concentrations in the liquid phase $\left[\mathrm{mg} \mathrm{L}^{-1}\right.$ liq], $C$ is the AT concentration in the total soil [ $\mathrm{mg} \mathrm{L}^{-1}$ tot], $\mu_{m}$ is the ADB growth rate $\left[\mathrm{day}^{-1}\right], K_{S}$ is the half-saturation constant $\left[\mathrm{mg} \mathrm{L}^{-1}\right.$ liq $], k_{\text {decay }}$ is the ADB decay rate $\left[\mathrm{day}^{-1}\right]$ and $Y[-]$ is the yield, i.e., the biomass formed per mass of pesticide degraded. Total soil AT degradation rate is related to the AT concentration in solution that, in turn, is directly related to solid phase AT concentration. Mathematically, this cannot be distinguished from an assumption that the degradation rate is related to solid phase concentration unless the parameter Ks is not fitted (as here) but derived from independent liquid batch studies.

Assuming AT concentrations that are low compared to the half-saturation constant $\mathrm{K}_{\mathrm{s}}$, this model is simplified to:

$\frac{d X}{d t}=\left(\mu_{m, \bmod } C_{l}\right) X-k_{\text {decay }} X$

$\frac{d C}{d t}=-\frac{1}{Y}\left(\mu_{m, \bmod } C_{l}\right) X$

where $\mu_{m, \text { mod }}=\mu_{m} / K_{s}\left[\mathrm{~L}_{\text {liq }} \mathrm{mg}^{-1} \mathrm{day}^{-1}\right]$ is referred to as the modified ADB growth rate. The information about $K_{s}$ values of pesticide degradation in soils is scarce and variable for different substrates and degrading populations (ranging from 0.0006 to $1314 \mathrm{mg} \mathrm{L}^{-1}$, (Alexander, 1999)). For AT mineralization Yassir et al. (1999) reported values for $K_{s}$ ranging from 0.26 to $8 \mathrm{mg} \mathrm{AT} \mathrm{kg}^{-1}$ soil. The mini-column studies performed here used initial AT concentration in a similar range, i.e. up to $5.4 \mathrm{mg} \mathrm{AT} \mathrm{kg}^{-1}$ soil. Moreover, as the shape of the batch degradation kinetics (see Results) did not allow determination of the $K_{s}$ parameter independent of the initial biomass, $C_{l}$ was neglected in comparison with $K_{s}$ and the simplified equations ( 3 and 4) were used. This simplified Monod model to describe degradation kinetics has been applied previously (De Wilde et al., 2009; Sniegowski et al., 2009).

Both physical and chemical non-equilibrium was neglected and the classical convection-dispersion equation $(\mathrm{CDE})$ was used to model reactive transport based on the leachate data. The $\mathrm{CDE}$ for one-dimensional flow of reactive solutes subject to adsorption and degradation in a homogeneous soil is described by:

$\frac{\delta}{\delta t}\left(\theta C_{l}+\rho_{b} C_{s}\right)=\frac{\delta}{\delta x}\left(\theta D \frac{\delta C_{l}}{\delta x}-J_{w} C_{l}\right)+\frac{d C}{d t_{\mathrm{deg}}}$

where $C_{s}$ is the AT concentration of the adsorbed phase $\left[\mathrm{mg} \mathrm{kg}^{-1}\right], D$ is the dispersion coefficient $\left[\mathrm{m}^{2}\right.$ day $\left.^{-1}\right], \theta$ is the volumetric water content $\left[\mathrm{L}_{\text {liq }} \mathrm{L}^{-1}\right.$ tot $], J_{W}$ is the volumetric water flux density [ $\left.\mathrm{m} \mathrm{day}^{-1}\right], \rho_{b}$ is the soil bulk density $\left[\mathrm{kg} \mathrm{L}^{-1}\right.$ tot $], x$ is distance [cm], $t$ is time [day] and $d C / d t_{d e g}$ is the change in total AT concentration due to degradation.

Linear sorption is used in this study to describe solute adsorption: 
Table 1

Lower and upper parameter bounds for relevant kinetic parameter used to fit the leachate data from the mini-columns.

\begin{tabular}{lll}
\hline & Lower bound & Upper bound \\
\hline $\mathrm{K}_{d}\left(\mathrm{~L}_{\text {liq }} \mathrm{kg}^{-1}\right)$ & 0 & 2 \\
$\mu_{m \text {, mod }}\left(\mathrm{L}_{\text {liq }} \mathrm{mg}^{-1} \mathrm{day}^{-1}\right)$ & $\exp (0.1)$ & $\exp (4)$ \\
$\mathrm{X}_{\text {ini }}\left(\mathrm{mg} \mathrm{L}^{-1} \mathrm{Tot}\right)$ & $\exp (-10.8)$ & $\exp (-0.2)$ \\
$\mathrm{k}_{\text {decay }}\left(\mathrm{day}^{-1}\right)$ & 0 & 0.5 \\
$\mathrm{Y}(-)$ & 0.2 & 0.7 \\
\hline
\end{tabular}

$C_{s}=K_{d} C l$

where $K_{d}$ is the adsorption coefficient $\left[\mathrm{L}_{\text {liq }} \mathrm{kg}^{-1}\right.$ ].

Equation (5) can be rewritten as

$R \frac{\delta C_{l}}{\delta t}=D \frac{\delta^{2} C_{l}}{\delta x^{2}}-\nu \frac{\delta C_{l}}{\delta x}+\frac{\delta C}{\theta \delta t_{\mathrm{deg}}}$

where $\nu=J_{w} / \theta$ is the averaged pore-water velocity [m day ${ }^{-1}$ ] and $R$ is the retardation factor given by

$R=1+\frac{\rho_{b}}{\theta} K_{d}$

Pesticide degradation can be described using the simplified Monod kinetics equation (4). No microbial transport was assumed, i.e. the dynamics of biomass $X$ is only determined by equation (3).

Equations (3), (4) and (7) have been implemented in HYDRUS-1D (Simunek et al. 2005) as previously used to predict metalaxyl and linuron leaching through a biofilter column (De Wilde et al. (2009)). The parameters $D, \nu$ and $\theta$ (equation (7)) could be estimated by fitting the CDE for non-reactive solutes to the observed $\mathrm{Br}^{-}$BTC. CXTFIT2 (Toride et al., 1995) uses the Levenberg-Marquardt algorithm to minimize the Root Mean Square Error (RMSE) between observed and predicted values.

Liu and Zachara (2001) showed that the parameters estimated for the ful Monod model from batch experimental data can have large uncertainties due to linear correlations between them. To avoid this uncertainty and as the parameter $X_{i n i}$ seems to have a low sensitivity, the value of this parameter was fixed at $10^{-8.8} \mathrm{mg}$ $\mathrm{L}^{-1}$ Tot for the inverse modelling of the presented data. Also the value of $Y$ was fixed and not considered for inverse modelling. The value used was calculated from an AT batch mineralization experiment involving the same soil in which $54 \%$ of the added AT was mineralized (Cheyns et al. unpublished data). Since there was no AT nor metabolites detected in the water extract of the soil after mineralization and sorption was neglected, it is assumed that $46 \%$ was incorporated into the $\operatorname{ADB}(Y=0.46)$, a simplification that was done before (Sniegowski et al., 2009) and is permitted due to the low sensitivity of parameter $Y$.

This model requires the estimation of 3 parameters, i.e.: $K_{d}, \mu_{m}$, mod and $k_{\text {decay }}$ and these parameters were calculated using the leachate data from the mini-columns irrigated at high flow rate (A and B). The leaching data from the mini-columns operated at lower flow rate ( $C$ and $D$ ) were used to evaluate the model.

\subsection{Sensitivity analysis: Morris' One-At-a-Time design}

A sensitivity analysis (SA) was conducted using the global SA One-At-a-Time design (Morris, 1991) that covers the entire space over which the parameters vary
(Mertens et al., 2005). The mean and standard deviation of the distribution of elementary effects for each parameter provides information about the influence of that parameter on the output. The Morris method was implemented in MATLAB (MathWorks, 2008) and a total of 1750 model evaluations were performed. Since we were interested in the parameter sensitivity over a large parameter range, large parameter bounds were chosen (Table 1). Parameter values of $\mu_{m, \bmod }$ and $X_{l, \text { ini }}$, were sampled between the log transformed parameter ranges.

\subsection{Shuffled complex evolution metropolis (SCEM) algorithm}

The Shuffled Complex Evolution Metropolis (SCEM) algorithm (Vrugt et al., 2003) was used to infer the posterior distributions of the model parameters. The SCEM algorithm aims at minimizing the objective function which is defined as the root mean square error (RMSE) between observed and predicted values. For details of the algorithm the reader is referred to Vrugt et al. (2003); Mertens et al. (2004) and Feyen et al. (2007), only a brief description is given below.

The SCEM algorithm starts by generating an initial population of s parameter sets sampled from the joint prior parameter distribution. The latter constrains the parameter space and represents the belief about the parameters before any data are collected. Independent uniform prior parameter distributions between realistic lower and upper bounds are typically adopted for each parameter. In this study, the lower and upper bounds presented in Table 1 are used as uniform prior distributions, the number of complexes was set equal to the number of model parameters included in the optimization, the population size was set to 90 , the maximum number of model evaluations to 7000 whilst other algorithm parameters were left to their default value. Once the posterior density has been computed for the s parameter combinations of the initial sample, the population is partitioned into q complexes. In each complex a parallel sequence is launched from the point with the highest posterior density. New candidate points are generated employing a multivariate normal distribution centered on the current draw of the sequence. The posterior density of new candidate points are calculated and the points are added (by random replacement) to the current sequence based on the Metropolis-annealing (Metropolis et al., 1953) criterion. After a predefined number of iterations the complexes are shuffled to share information gained independently in the parallel sequences.

Vrugt et al. (2003) propose to use the Gelman and Rubin (1992) criteria (GR) for the evaluation of the convergence of the sampler to the stationary posterior distribution. In this study, this recommendation is followed and the distribution is called stationary when $G R \leqq 1.2$.

The optimization tool was implemented in Matlab (MathWorks, 2008) and coupled with Hydrus-1D.

\section{Results and discussion}

\subsection{Bromide break-through curve}

The parameters $D, \nu$ and $\theta$ were estimated from the fit of the CDE equation (7) to the observed bromide BTCs (Fig. 1), using CXTFIT2 (Toride et al., 1995). The CDE model described the experimental data well with $R^{2}$ values varying between 0.92 and 0.99 . The BTCs did not show any significant asymmetry or long tailing that indicate physical non-equilibrium. The differences in BTCs of the mini-

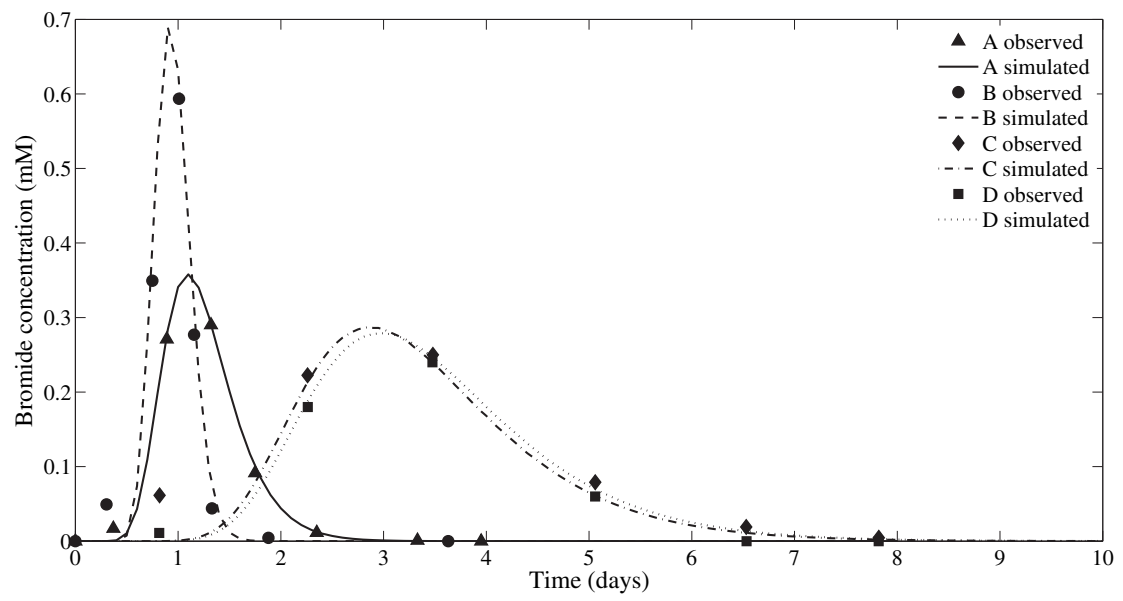

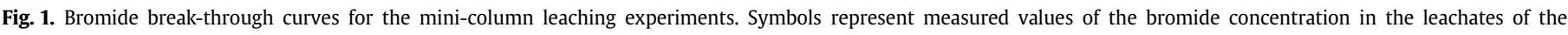
mini-columns and lines represent the simulated values of the bromide concentrations. 
Table 2

Soil hydraulic parameters obtained from fitting the CDE to the observed bromide BTCs.

\begin{tabular}{lll}
\hline Mini-column & Volumetric water content $\theta$ & Dispersion length $\lambda(\mathrm{cm})$ \\
\hline $\mathrm{A}$ & 0.35 & 0.35 \\
$\mathrm{~B}$ & 0.26 & 0.11 \\
$\mathrm{C}$ & 0.34 & 0.40 \\
$\mathrm{D}$ & 0.35 & 0.41 \\
\hline
\end{tabular}

columns A and B can be due to small differences in column packing. The volumetric water content $\theta$ and dispersion length $\lambda=\frac{D}{v}(\mathrm{~cm})$ are shown in Table 2. These values were used as parameters for describing AT transport in the mini-columns using HYDRUS1-D.

\subsection{Transport of atrazine in the mini-column experiment}

AT concentrations found in the collected leachates of minicolumns A and B are shown in Fig. 2.

After a short retardation, AT peaked in the effluent at concentrations identical to the influent. This concentration $\left(12 \mathrm{mg} \mathrm{L}^{-1}\right.$, $\pm 2 \mathrm{mg} \mathrm{L}^{-1}$ ) was maintained during 9 days. The observed variation is probably due to measurements errors and some evaporation in effluent bottles. Subsequently, the concentration of AT in the effluent decreased, while AT supply was sustained. These results reflect a lag phase for initiating degradation. This pattern can be interpreted and modelled as an ADB initially present in the subsoil at low cell numbers, that is growing on the expense of AT until the ADB is sufficiently large to observe degradation of AT (Alexander, 1999).

When AT was added again in step 2 after a leaching period without AT of 161 days, AT concentration increased in the effluent samples but peak height concentration was maximally $82 \%$ of the influent concentration. The shorter lag period during step 2 indicates that the size of the ADB was larger at the beginning of step 2 compared to that at day 1 .

\subsection{Sensitivity analysis: Morris' One-At-a-Time design}

The absolute value of the mean and the standard deviation of the elementary effect distribution of each parameter against the RMSE of the observed AT concentration measured during the minicolumn A experiment is plotted in Fig. 3. Unlike most other SA, the sensitivity of parameters in the Morris method cannot be quantified since it is not based on a statistic test that allows acceptance or rejection on a $5 \%$ significance level. Therefore, only a qualitative

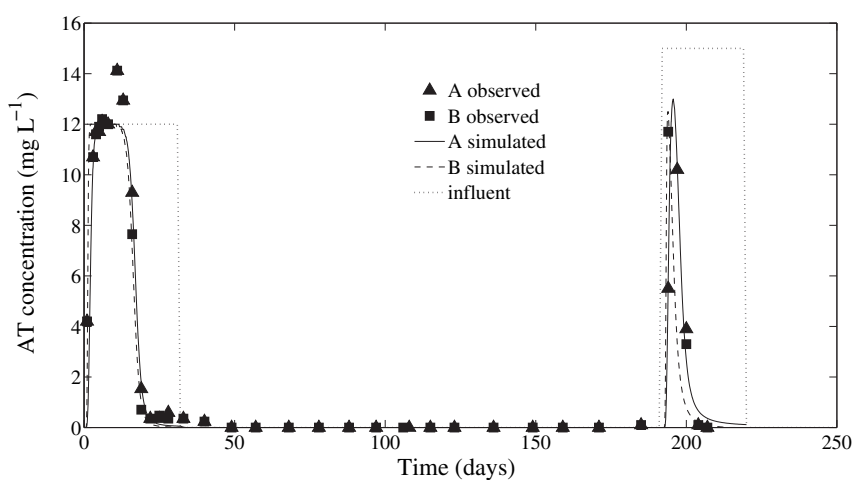

Fig. 2. Measured (full symbols) and simulated (lines) AT concentration in the minicolumn leachates in function of the time for mini-columns A and B, irrigated at high flow rate. The dotted line represents the atrazine concentration in the influent. Limit of quantification was $1 \mathrm{mg} \mathrm{L}^{-1}$

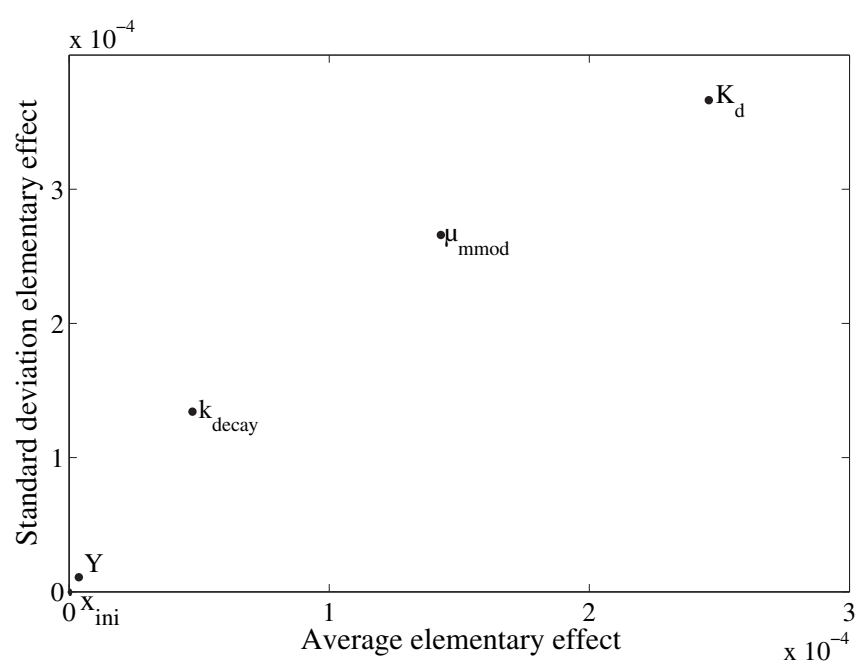

Fig. 3. Absolute value of the mean and standard deviation of the elementary effect distribution of each model parameter as calculated using the Morris Sensitivity Analysis.

ranking of the importance of parameters with respect to overall importance and interaction with other parameters or non-linear effects can be performed. Fig. 3 shows that the sensitivity of the transport model to the value of $Y$ and $X_{i n i}$ is very low within the broad range of values used (Table 1 ) since it has a low overall effect and a small interaction with other parameters (or non-linear effect in parameter space). Fig. 3 also shows that $K_{d}$ and $\mu_{m \text {, mod }}$ are the most sensitive parameters for the model. Besides those parameters, the model is also sensitive to the $k_{\text {decay }}$ value.

\subsection{Shuffled Complex Evolution Metropolis (SCEM) algorithm}

The fit of the HYDRUS-1D model with implemented simplified Monod kinetics to the observed values of mini-columns A and B in Fig. 2 is a result of a global optimization using the SCEM algorithm between the parameter bounds shown in Table 1. The SCEM succeeded for both mini-column experiments in optimizing the posterior parameter distribution of the 3 parameters and converged after 5076 (mini-column A) and 1332 (mini-column B) model evaluations, optimized parameters are given in Table 3. Fig. 2 illustrates that the model describes AT leaching well during both step applications. No correlations were found between the converged parameters (data not shown). $K_{d}$ values differed between the mini-columns but both values are extremely small as expected at low organic matter content of the soil $(0.4 \% \mathrm{C})$. The $K_{d}$ value was a very sensitive parameter for the position of the peak of the AT break-through curve but less for the area of the peak, i.e. the amount leached through the soil columns. As the latter was of main interest for this study, the $K_{d}$ value was fitted to obtain the best fit for the retardation factor and not fixed to values determined from batch experiments.

The posterior cumulative parameter distribution of the 3 optimized parameters is shown in Fig. 4 . The parameter ranges on the $x$-axes in this figure correspond to the lower and upper bounds

Table 3

Parameter sets for the mini-columns irrigated at high flow rate (A and $\mathrm{B})$, corresponding to the model fit with the lowest Root Mean Square Error.

\begin{tabular}{llll}
\hline & $\mathrm{K}_{d}\left(\mathrm{~L} \mathrm{~kg}^{-1}\right)$ & $\mu_{m, \bmod }\left(\mathrm{L} \mathrm{mg}^{-1} \mathrm{day}^{-1}\right)$ & $\mathrm{k}_{\text {decay }}\left(\mathrm{day}^{-1}\right)$ \\
\hline Mini-column A & 0.206 & 87.50 & 0.041 \\
Mini-column B & 0.001 & 84.92 & 0.031 \\
\hline
\end{tabular}


Column A
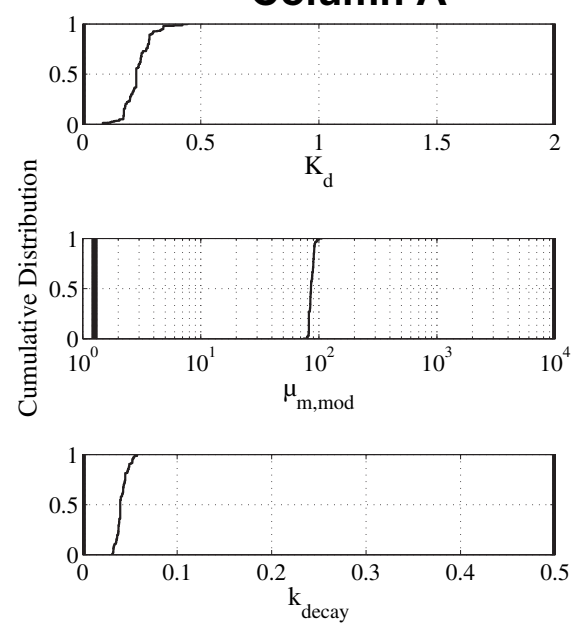

Column B
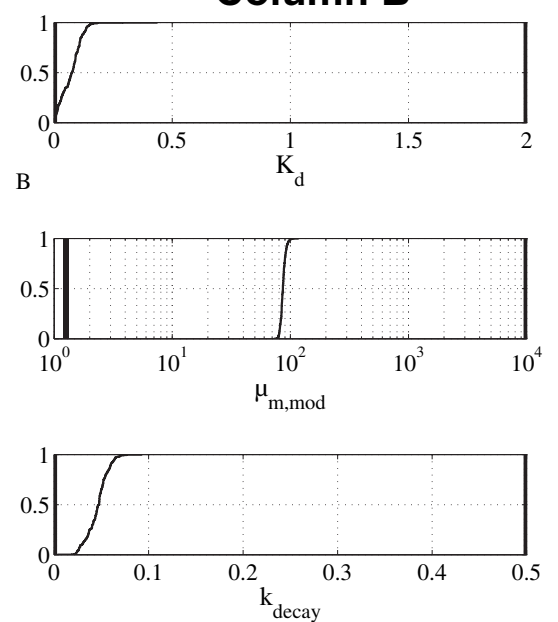

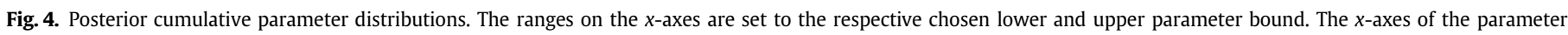
$\mu_{m, \bmod }$ are $\log$ transformed.

used in the inverse modelling. A narrow posterior parameter distribution, corresponding to a narrow confidence interval, is obtained for all 3 parameters, which confirms the high sensitivity of the parameters as predicted with the Morris SA.

\subsection{Model evaluation: batch degradation experiments}

The model was evaluated by performing batch degradation tests in soil from the mini-columns before and after the leaching experiment. Fig. 5 shows the AT concentration as a function of time for these experiments. Before AT application the lag period for AT degradation in the soil was about 40 days. This lag period became shorter in the soil sampled from the mini-columns after exposure to AT. Furthermore, the lag period was longer with soil sampled from the bottom of the mini-columns compared to that with soil sampled from the top of the mini-columns.

The batch experiments were fitted with the model with fixed parameters from the mini-column experiment except $X_{\text {ini }}$. The results of the fits using the SCEM algorithm are shown in Fig. 5 and the parameters obtained from the fits are given in Table 4. To compare the values obtained from the batch suspension and minicolumn experiment, the $X_{i n i}$ values are calculated as mg biomass per $g$ dry weight soil since the solid-liquid ratio differed between the 2 experiments.

The values in Table 4 show that the biomass concentration in the initial soil is larger when predicted from the mini-column experiment than estimated from the batch degradation experiment, however, both values illustrate a very small ADB. The column degradation was only analysed after a leaching period at $20^{\circ} \mathrm{C}$, while batch degradation experiments were performed with fresh soil samples from the fridge, this can somewhat influence the biomass concentration. In any case, despite significant differences in predicted biomass, the analysis confirms that the relative effects of pre-exposure on the lag phase are similar in batch as in columns. Initially there is a very small AT degrading population, this population is larger at the end of the experiment in both the top and bottom layer of the soil mini-column. In addition, the obtained value for ADB concentration is larger in the soil from the top layer than in de soil from the bottom layer, as can be predicted using the model (see below).
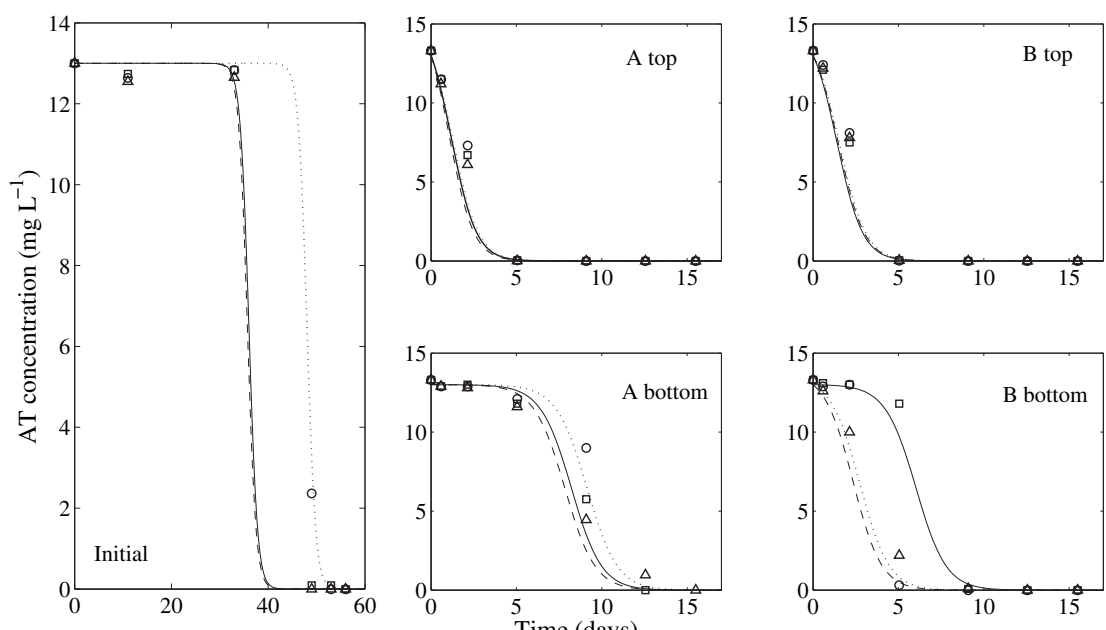

$\begin{array}{cc}\Delta & \text { observed a } \\ \circ & \text { observed b } \\ \square & \text { observed c } \\ - & -\end{array}$
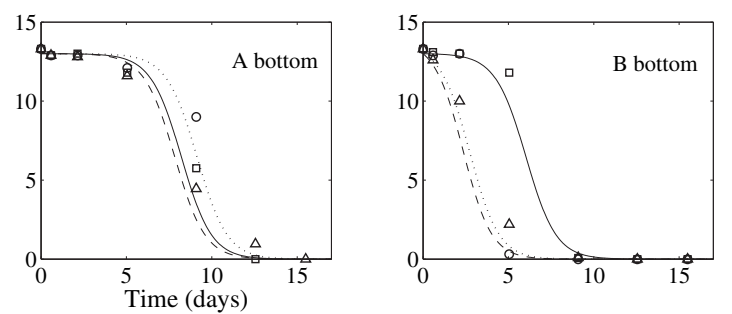

simulated b

- simulated $c$

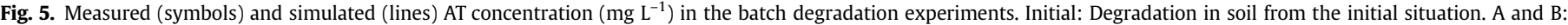

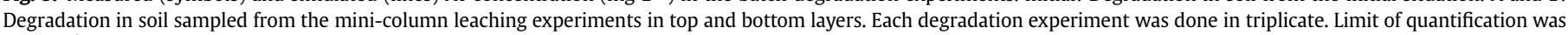
$1 \mathrm{mg} \mathrm{L}^{-1}$ 


\section{Table 4}

Biomass $(\mathrm{X})$ concentration $\left(\mathrm{mg} \mathrm{g}^{-1}\right.$ ) predicted by the model calibration to the minicolumn data or observed in corresponding batch degradation experiments. $\log (\mathrm{X})$ values of -9 correspond to a lag period of about 14 days, values of -3 to about 4 days and $>-1$ to less than 1 day. The model calibration used constant yield and degradation rate parameters for both setups. Values in brackets are standard deviations for 2 mini-columns.

\begin{tabular}{lll}
\hline & $\log (\mathrm{X})\left(\mathrm{mg} \mathrm{g}^{-1}\right)$ & \\
\cline { 2 - 3 } & obtained from column data & observed in batch degradation \\
\hline Initial soil & $-9.0^{\mathrm{a}}$ & -19.9 \\
Top layer & $-0.8( \pm 0.2)^{\mathrm{b}}$ & $-1.7( \pm 0.1)$ \\
Bottom layer & $-3.7( \pm 0.1)^{\mathrm{b}}$ & $-3.8( \pm 1.5)$ \\
\hline
\end{tabular}

a Value was fixed initially

b Values predicted with the mini-column transport model for day 220.

\subsection{Model evaluation: mini-columns at lower flow rate}

The effluent concentration for the mini-columns at low flow were predicted using the mean parameters obtained from the calibration of the model with the data from the mini-columns operated at high flow rate (Table 3 ). AT concentration measurements and predictions are shown in Fig. 6. It is clear that the predicted results approach the observed results, but a discrepancy between the observed and predicted values is observed for AT break-through during the second step application. However, the concept as seen at high flow rate is confirmed when analysing and modelling the columns at low flow rate. Less AT is leached during the second step application due to a shorter lag time for degradation during the second step application. In addition, the model predicts lower peak AT concentrations at lower flow rate, which confirms the measurements. At the low flow rate, predicted AT peak concentrations in the second step are only 60\% of influent concentrations whereas this was $82 \%$ at high flow rate. Corresponding measured values were $23 \%$ of the influent concentration $( \pm 16 \%)$ at low flow rate and $73 \%( \pm 7 \%)$ at high flow rate.

\subsection{Population dynamics}

Using the model the ADB size dynamics in the soil mini-columns can be simulated. Fig. 7 shows this simulation of the ADB size dynamics on top, in the middle and at the bottom of mini-column a. The simulations for the other mini-column showed similar results. Growth of the ADB is predicted to be largest in the top of the minicolumn, as that population is exposed to higher concentrations of AT. The difference in leaching of AT, as a fraction of the total input,

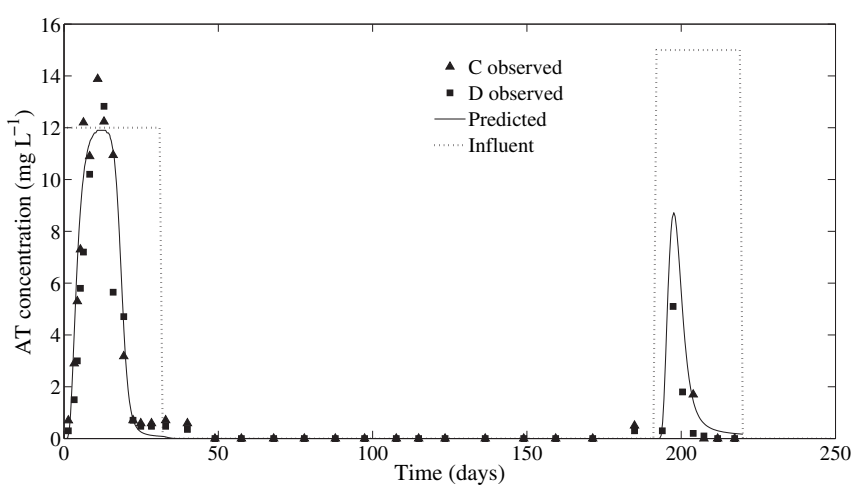

Fig. 6. Measured (full symbols) and predicted (lines) AT concentration in the minicolumn leachates for mini-columns $C$ and $D$, irrigated at low flow rate. The dotted line represents the AT concentration in the influent. The model was calibrated to data obtained from mini-columns A and B, irrigated at high flow rate. Limit of quantification was $1 \mathrm{mg} \mathrm{L}^{-1}$

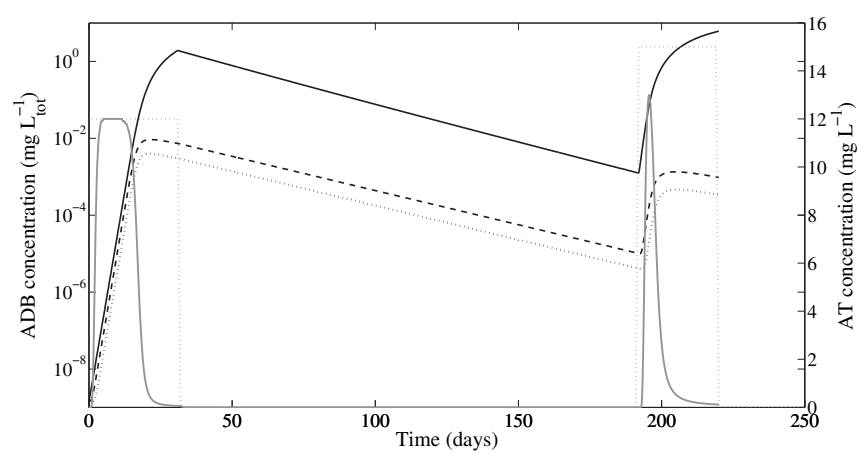

Fig. 7. Simulated atrazine degrading biomass concentration $\left(\mathrm{mg} \mathrm{L}^{-1}\right.$ Tot $\log$ trans formed) in the top (full line), middle (dashed line) and bottom (dotted line) of minicolumn A. Grey lines represent the simulated AT concentration in the influent (dotted line) and effluent (full line) solutions.

between the 2 step applications can be explained by the size of the ADB at the beginning of each step AT application.

The observed results and model fits indicate that the incorporation of the Monod-linked degradation kinetics in pesticide transport models is able to predict pesticide leaching. We have chosen to work with a subsoil and not topsoil because the former received less, and less frequently, pesticides than the latter, however, the subsoil acts as a main biotic filter before the leachates move to groundwater where degradation activity is limited. The proposed model obviously needs more parameters than a first-order model. The $K_{s}$ values can be determined by performing batch degradation experiments. $X_{\text {ini }}$ can be measured by Real Time-quantitative PCR of genes responsible for AT degradation. The yield can be determined more precise by performing ${ }^{14} \mathrm{C}$ mineralization experiments and measuring the amount of ${ }^{14} \mathrm{C}$ incorporated into the biomass. All these methods are time and cost consuming and the parameters obtained are vulnerable to external factors (climate, soil depth, ....). More research is needed to relate such parameters with soil-, climatic and soil management parameters before the proposed model can be used to predict leaching under field conditions.

It is clear that population dynamics are important to estimate the degradation potential of a soil population. Moreover, when SOM is low, degradation kinetics become of main importance to predict the transport of pesticides in the unsaturated soil towards groundwater. During the lag phase of growth of the pesticide degrading bacteria, it is possible that not sufficient pesticide degrading bacteria are present in the soil to perform significant pesticide degradation. This situation results in a high leaching potential of this pesticide. Sniegowski et al. (2009) showed that pesticide transport models in biofilters not taking into account the pesticide degrading biomass dynamics underestimated the risk of break-through of the pesticides.

Fig. 7 indicates that the decay rate of the ADB is much slower than the growth rate, this can explain the buildup of pesticide degrading bacteria after different pesticide applications in the field. In the field, pesticides are applied in high concentrations (e.g. $0.5 \mathrm{~g} \mathrm{~L}^{-1}$ ) as a short pulse and the flow rates can be tenfold below the lowest flow imposed here. Our model predicts vanishingly low peak AT concentrations at these concentrations and flow rates, at $10 \mathrm{~cm}$ depth in leachates, even when only a very small ADB is initially present. However, in natural systems growth rate of the biomass can be slower due to lower temperatures and at less optimal conditions. In addition, the decay of the pesticide degrading biomass can be large when periods in between different pesticide applications are long. It is clear that testing under field relevant conditions is required to assess if first-order models 
indeed underestimate pesticide break-through. Such experiments should use undisturbed soil columns with soil from a large part of the soil profile. The AT application should reflect common agricultural practice, i.e. a large concentration during a short pulse. Columns should be incubated outside, subjected to natural climatic conditions, and in the presence of crops.

\section{Conclusion}

The transport break-through of pesticides in mini-columns and the reduced lag phase after pre-exposure suggest that first-order degradation models do not describe the fate of atrazine in soil. Different mechanisms may explain the lag phase and effects of preexposure conditions. This was successfully modelled as Monod kinetics indicating growth of an atrazine degrading biomass when atrazine is present. Comparison with parameters obtained by fitting batch experiment results show the same trends as predicted from the mini-column transport model, confirming the predictions for the population dynamics.

\section{Acknowledgments}

This research was funded by the onderzoeksfonds K.U.Leuven under the project number GOA/2006/07-TBA.

\section{References}

Alexander, M., 1999. Biodegradation and Bioremediation. Academic Press, New York Bending, G., Rodriguez-Cruz, M., 2007. Microbial aspects of the interaction between soil depth and biodegradation of the herbicide isoproturon. Chemosphere 66 (4), 664-671.

Coquet, Y., Barriuso, E., 2002. Variability of pesticide adsorption within the topsoil of a small agricultural catchment. Agronomie 22, 389-398.

De Wilde, T., Mertens, J., Simunek, J., Sniegowksi, K., Ryckeboer, J., Jaeken, P., Springael, D. Spanoghe, P., Feb. 2009. Characterizing pesticide sorption and degradation in microscale biopurification systems using column displacement experiments. Environ. Pollut. 157 (2), 463-473.

Dubus, I.G., Beulke, S., Brown, C.D., Gottesburen, B., Dieses, A., 2004. Inverse modelling for estimating sorption and degradation parameters for pesticides. Pest Manage. Sci. 60 (9), 859-874.

Feyen, L., Vrugt, J.A., Nualláin, B., van der Knijff, J., De Roo, A., Jan. 2007. Parameter optimisation and uncertainty assessment for large-scale streamflow simulation with the lisflood model. J. Hydrol 332 (3-4), 276-289.

Fomsgaard, I.S., Oct. 1997. Modelling the mineralization kinetics for low concentrations of pesticides in surface and subsurface soil. Ecol. Model. 102 (2-3), 175-208.
Gelman, A., Rubin, D., 1992. Inference from iterative simulation using multiple sequences. Statist. Sci. 7, 457-472.

Jobbagy, E.G., Jackson, R.B., 2000. The vertical distribution of soil organic carbon and its relation to climate and vegetation. Ecol. Appl. 10 (2), 423-436.

Jones, S.H., Alexander, M., 1986. Kinetics of mineralization of phenols in lake water. Appl. Environ. Microbiol. 51 (5), 891-897.

Liu, C.X., Zachara, J.M., Jan. 2001. Uncertainties of monod kinetic parameters nonlinearly estimated from batch experiments. Environ. Sci. Technol. 35 (1), 133-141.

MathWorks, 2008. Using Matlab, Version R2008a. The Mathworks Inc., MA, USA.

Mertens, J., Madsen, H., Feyen, L., Jacques, D., Feyen, J., 2004. Including prior information in the estimation of effective soil parameters in unsaturated zone modelling. J. Hydrol 294 (4), 251-269.

Mertens, J., Madsen, H., Kristensen, M., Jacques, D., Feyen, J., 2005. Sensitivity of soil parameters in unsaturated zone modeling and the relation between effective, laboratory and in situ estimates. Hydrol. Process 19 (8), 1611-1633.

Metropolis, N., Rosenbluth, A., Rosenbluth, M.N., Teller, A., Teller, E., 1953. Equations of state calculations by fast computing machines. J. Chem. Phys. 21, 1087-1091.

Monod, J., 1949. The growth of bacterial cultures. Annu. Rev. Microbiol. 3, 371-394.

Morris, M., 1991. Factorial sampling plans for preliminary computational experiments. Technometrics 33, 161-174.

Shelton, D.R., Doherty, M.A., Jul. 1997. Estimating losses of efficacy due to pesticide biodegradation in soil: model simulations. Soil Sci. Soc. Am. J. 61 (4), 1085-1090.

Simkins, S., Alexander, M., 1984. Models for mineralization kinetics with the variables of substrate concentration and population density. Appl. Environ. Microbiol. 47, 1299-1306.

Simunek, J., Van Genuchten, M.T., Sejna, M., 2005. The HYDRUS-1D Software Package for Simulating the One-dimensional Movement of Water, Heat and Multiple Solutes in Variably-saturated Media, Version 4.05. Department of Environmental Sciences, University of California Riverside, Riverside, California, USA.

Sniegowski, K., Mertens, J., Diels, J., Smolders, E., Springael, D., 2009. Inverse modeling of pesticide degradation and pesticide-degrading population size dynamics in a bioremediation system: parameterizing the monod model. Chemosphere 75 (6), 726-731.

Spark, K.M., Swift, R.S., Oct. 2002. Effect of soil composition and dissolved organic matter on pesticide sorption. Sci. Total Environ. 298 (1-3), 147-161. b09.

Tiktak, A., van der Linden, A.M.A., Swartjes, F., 1994. Pestras: A one dimensional model for assesssing leaching and accumulation of pesticides in soil. RIVM report 715501003 , Bilthoven the Netherlands.

Toride, N., Leij, F., van Genuchten, M., 1995. The CXTFIT2 Code for Estimating Transport Parameters from Laboratory or Field. Version 2.0. Research Report No. 137. US Department of Agriculture, Riverside, California.

Vanderheyden, V., Debongnie, P., Pussemier, L., 1997. Accelerated degradation and mineralization of atrazine in surface and subsurface soil materials. Pestic. Sci. 49, 237-242.

Vrugt, J.A., Bouten, W., Gupta, H.V., Hopmans, J.W., Feb. 2003. Toward improved identifiability of soil hydraulic parameters: on the selection of a suitable parametric model. Vadose Zone J. 2 (1), 98-113.

Yassir, A., Lagacherie, B., Houot, S., Soulas, G., 1999. Microbial aspects of atrazine biodegradation in relation to history of soil treatment. Pestic. Sci. 55 (8), 799-809. 